\title{
Operational Evaluation of VEGGIE Food Production System in the Habitat Demonstration Unit
}

\author{
Gary W. Stutte ${ }^{1}$ and Gerard Newsham. ${ }^{2}$ \\ ESC-Team QNA, Kennedy Space Center, FL 32899 \\ Robert M. Morrow ${ }^{3}$ \\ Orbitec, Madison, WI \\ and \\ Raymond M. Wheeler ${ }^{4}$ \\ NASA, Kennedy Space Center, FL 32899
}

\begin{abstract}
The 2010 Desert Research and Technology Studies (DRATS) of the VEGGIE Food Production System in the Habitat Demonstration Unit (HDU) Pressurized Excursion Module (PEM) was the first operational evaluation of salad crop production technology in a NASA analog test. A systematic evaluation of rooting media and nutrient delivery systems were evaluated for three lettuce cultivars that have shown promise as candidates for a surface based food production system. The VEGGIE nutrient delivery system worked well, was able to be maintained by multiple operators with a minimum of training, and supported excellent lettuce growth for the duration of the test. A Hazard Analysis and Critical Control Point (HACCP) evaluation was performed using ProSan ${ }^{\text {tm }}$ as sanitation agent prior to consumption was approved, and the crew was allowed to consume the lettuce grown using the VEGGIE light cap and gravity based nutrient delivery system at the completion of the 14-day DRAT field test. The DRAT field test validated the crew operations; Growth of all lettuce cultivars was excellent. The operational DRAT field testing in the HDU identified light quality issues related to morphology and pigment development that will need to be addressed through additional testing. Feedback from the crew, ground support personnel, and human factors leads was uniformly positive on the psychological value of having the crop production system in the excursion module. A number of areas have been identified for future work, to minimize the "footprint" of the Food Production system through creative use of unused wall and floor space in the unit. (Funded through NASA KSC FY10 CTC
\end{abstract} grant)

$\begin{array}{ll}\text { DRATS } & \text { Desert Research and Technology Studies } \\ H D U & =\text { Habitat Demonstration Unit } \\ P E M & =\text { Pressurized Logistics Module } \\ C T C & =\text { Core Technical Capabilities } \\ H A C C P & =\text { Hazard Analysis and Critical Control Point } \\ \text { PAR } & =\text { Photosynthetically Active Radiation } \\ \text { FY } & =\text { Fiscal Year } \\ \text { ESMD } & =\text { Exploration Systems Mission Directorate } \\ \text { LSSPO } & =\text { Lunar Surface Systems Project Office }\end{array}$

${ }^{1}$ Senior Scientist, Space Life Science Laboratory, Mail Code ESC-53.

${ }^{2}$ Scientist I, Space Life Science Laboratory, Mail Code ESC-53.

${ }^{3}$ Senior Scientist

${ }^{4}$ Surface Systems Lead, Mail Code NE-S-1 


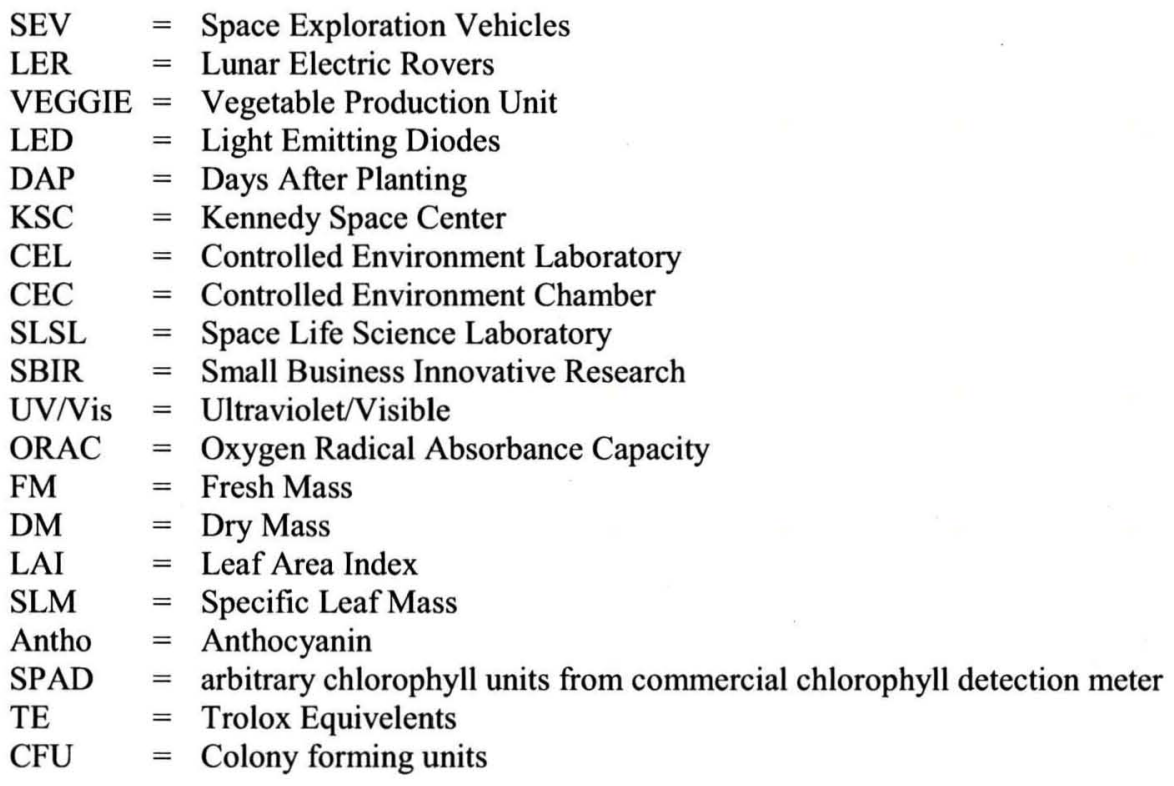

\section{Introduction}

Long-duration lunar outpost will rely entirely upon imported or preserved foods to sustain the crew during the early missions. Fresh perishable foods would be consumed soon after delivery by the re-supply missions. Growing fresh produce, such as salad crops, in the lunar outpost would greatly improve the dietary acceptability and provide bioavailable antioxidants for the crew in the high radiation lunar environment. Although controlled environment research has been carried out on the growth of salad crops under a range of environmental conditions, there has been no demonstration of sustained production in a flight-like system under conditions that might be encountered in space. There are several fundamental challenges which must be overcome in order to achieve sustained production. These include growing multiple species, sustaining productivity through multiple plantings, and minimizing time for the human factor operations.

In June 2009, the Lunar Surface Systems Habitat Demonstration Unit (HDU) was initiated. The HDU project is a project that integrates technologies and innovations from numerous NASA centers, and will be used to investigate and validate surface architectures, operations concepts, and requirements definition. The HDU evaluation was a key component of the 2010 Desert Research and Technologies Simulations (D-RATS). The HDU project is part of the strategic plan from the Exploration Systems Mission Directorate (ESMD) Integration Office and the Lunar Surface Systems Project Office (LSSPO) to test surface elements in a surface analog environment which includes two Space Exploration Vehicles [SEV's, formerly known as Lunar Electric Rovers (LER's)] and the HDU during the 2010 analog field test.

A food production system was identified as technology from KSC to be evaluated in the HDU. This project was designed to to improving the rooting matrix, and advancing the operations for field testing of a food production unity in the NASA-led multi-center HDU Project. The purpose of these experiments is to develop, integrate, test, and evaluate a food production system that is consistent with the HDU mission architectures and surface operations.

This research had three distinct, but overlapping, components:

1. Define rooting media, nutrient delivery, and water management of lettuce under anticipated HDU PEM environmental conditions.

2. Develop a HACCP Plan to minimize risk of consumption of fresh lettuce.

3. Evaluate VEGGIE performance duringthe 2010 HDU PEM DRATS field test.

Each of these developmental components will be discussed independently and a final assessment of the performance during the integrated 2010 DRAT test is provided. 


\section{Baseline growth of three lettuce cultivars under VEGGIE LED array prior to integration into the HDU}

The objective of these experiments was to establish the baseline growth response of three Lactuca sativa L. cultivars grown under the VEGGIE LED array under environmental conditions anticipated for the HDU. Prior testing had indicated that a commercial peat/vermiculite mixture is an acceptable media for VEGGIE HDU testing since it has excellent aeration, good water holding capacity, and tends to form a rooting matrix in the root zone. This is in contrast with arcillite, a montmorillonite clay, which also provides good aeration, but has a narrower range of water retention than peat/vermiculite, and is more susceptible to disturbance and spillage when plant trays are moved. This resulted in an early decision to utilize a peat/vermiculite mix (Sunshine LP5 Mix, Sungro, Bellview, WA) in the final DRAT HDU PEM VEGGIE testing. Experiments were performed to evaluate the effect of 7.5 and $15 \mathrm{~g} / \mathrm{l}$ of the controlled release fertilizer, Osmocote ${ }^{\circledR}$ Plus 15-9-12 (Scotts, Maryville, $\mathrm{OH}$ ) on growth of the Outredgeous, Flandria, and Firecracker lettuce cultivars using the methods described above.

\section{A. Experimental Protocols}

1. Cultivars: Two red, loose leafed Lactuca sativa L. cultivars (Outredgeous and Firecracker) and one greenbibb type lettuce cultivar (Flandria) were used in these experiments. Seeds were sown at a density of 6 seeds per pot, and then thinned to 1 plant per pot between 10-14 days after planting (DAP). Lettuce was harvested at 28 DAP.

2. Environmental Parameters: The experiment were maintained in the Space Life Sciences Laboratory (SLSL), Controlled Environment Lab (CEL), CEC 3 was set to maintain air temperature at $23^{\circ} \mathrm{C}$, relative humidity at $45 \%$, and $\mathrm{CO}_{2}$ at $1200 \mu \mathrm{mol} \mathrm{mol}^{-1}$. Lights were provide with red $(660 \mathrm{~nm})$, blue $(440 \mathrm{~nm})$ and green $(530 \mathrm{~nm})$ LEDs of the $1^{\text {st }}$ Generation VEGGIE Light array. The VEGGIE arrays were developed by Orbitec as part of a Phase I SBIR grant though KSC. Three VEGGIE arrays were used in these experiments, and each had independent light and photoperiod control. These setpoints were established using software and timers that reside on each of the chambers. All experiments were performed under continuous light at $\sim 240 \mu \mathrm{mol} \mathrm{m}^{-2} \mathrm{~s}^{-1}$ PAR from either the $1^{\text {st }}$ generation VEGGIE LED array.

The VEGGIE did not have active environmental control, so the environmental conditions established in an Environment Growth Chamber (EGC Model M-48, EGC, Chagrin Falls, $\mathrm{OH}$ ) and passively managed in the VEGGIE, by facilitating air flow across the plants by fans in the lamp cap. The air temperature, $\mathrm{RH}$ and $\mathrm{CO}_{2}$ conditions were similar to ambient conditions in CEC.

Soil moisture content was maintained in media by wicking moisture from a capillary mat. The soil moisture is a function of the moisture content of the capillary mat, particle size and depth of the media. This was determined experimentally to maintain $\sim 50 \%$ soil moisture content for the duration of the experiment.

3. Biometric Measurements: At harvest biometric measurements (i.e. plant height, canopy width, canopy fresh weight and leaf area) were determined. Plant tissues were oven-dried at $70^{\circ} \mathrm{C}$ for $72-96 \mathrm{~h}$ to determine dry mass.

4. Evapotranspiration Measurements: Nutrient additions to the nutrient delivery system (NDS) modules were obtained daily. Since the nutrient additions are driven by evapotranspirative demand of the plants, this was used to estimate daily and total evapotranspiration. Water usage during the germination period (typically 3-5 days) was used as the baseline evaporative demand of the chambers.

5. Chlorophyll Measurements:_At harvest, non-destructive leaf chlorophyll measurements were determined using a Minolta SPAD model 502 chlorophyll meter.

6. Color development: Non-destructive measurements of leaf pigment intensity and color were obtained using a Konica CR 400 Chroma-meter (Konica Minolta Photo Imaging, Mahwah, NJ) on nine plants from each cultivar. Each measurement consisted of three readings from separate leaves. Data was collected using the CIE 1976 
$\mathrm{L}^{*} \mathrm{a}{ }^{*} \mathrm{~b}^{*}$ values The CIE color scale uses a three dimensional scale to describe a color. The $\mathrm{L}^{*}$ describes lightness or darkness from $L^{*}=0$ (dark) to $L^{*}=100$ (light). The $a^{*}$ describes the redness or greenness with $-a^{*}$ values showing increased green and $+a^{*}$ increasing red. The $b^{*}$ describes the yellowness or blueness with $-b^{*}$ showing increasing blue and $+\mathrm{b}^{*}$ showing increasing yellow.

7. Bioprotectant Analysis. Leaf samples of plants used for color analysis were quickly chopped into small sections, mixed, and $\sim \mathrm{g}$ samples were collected and frozen in liquid $\mathrm{N}_{2}$ following harvest for analysis of total anthocyanin content and antioxidant potential. Samples were stored either on dry ice or a $-80{ }^{\circ} \mathrm{C}$ freezer until analysis was performed. The frozen tissue was extracted in acidified methanol for analysis.

i. Anthocyanin analysis. Methanol extracts were measured for absorbance at $530 \mathrm{~nm}$ (for anthocyanin content) and $650 \mathrm{~nm}$ (for chlorophyll content) using a Beckman DU530 UV/Vis Spectrophotometer (Beckman Coulter, Inc., Fullerton, CA). Since chlorophyll contributes to the absorbance of the sample at $530 \mathrm{~nm}$, a correction coefficient was used in the anthocyanin calculation as described by Mancinelli et al. (1975). Plant sample absorbance's were compared against a standard curve prepared from kuromanin chloride (CAS No. 7084-24-4, Sigma-Aldrich, St. Louis, MO) in extraction solvent.

ii. Antioxidant analysis. Methanol extracts were analyzed for antioxidant potential using the oxygen radical absorbance capacity (ORAC) assay as described by Ou et al. (2001) using a Tecan GENios Pro plate reader (Tecan, Salzburg, Austria) equipped with a dual injection port solvent addition system. The area under the fluorescence decay curve was compared against a standard curve prepared by analyzing increasing concentrations of Trolox [6hydroxy-2,5,7,8-tetramethyl-chroman-2-carboxylic acid], a water soluble Vitamin E analog. ORAC antioxidant values were reported as $\mu \mathrm{mol}$ Trolox equivalents (TE) per gram of plant sample.

\section{B. RESULTS}

Increasing the concentration of Osmocote $\AA$ from 7.5 to $15 \varepsilon$ of media resulted in a $50 \%$ increase in plant height, $2.8 \mathrm{X}$ increase in fresh mass (FM), 3.1X increase in dry mass (DM) and $2.9 \mathrm{X}$ increase in leaf area of Outredgeous (Table 6). This is reflected in the 2.9X higher leaf area index (LAI), as well as $9 \%$ reduction in specific leaf mass (SLM). Increasing the concentration of Osmocote ${ }^{\circledR}$ also resulted a reduction in the* and $b^{*}$ color values, which produces a less intense purple color of the leaf. There was an increase in chlorophyll concentration, and slight reduction (7\%) in anthocyanin concentration. The instrumentation for measuring ORAC failed and could not be repaired, so it's not possible to assess the effect on antioxidant potential at this time. The increase in plant size is likely due to the higher concentration of nitrogen $(\mathrm{N})$ in media, which is consistent with the higher concentration of chlorophyll in the leaf.

Table 1: Effect of Osmocote $®$ concentration on the growth and quality of Lettuce cv. Outredgeous grown on commercial peat/vermiculate mix under VEGGIE LED array (mean + standard error) .

\begin{tabular}{|c|c|c|c|c|c|c|}
\hline & \multicolumn{6}{|c|}{ Biometric Data } \\
\hline $\begin{array}{l}\text { Osmocote } \\
{[\mathrm{g} / \mathrm{L}]}\end{array}$ & Height, $\mathrm{mm}$ & FM, g & $\mathrm{DM}, \mathrm{g}$ & Area. $\mathrm{cm}^{2}$ & LAI & $\mathrm{SLM}, \mathrm{mg} \mathrm{cm}^{-2}$ \\
\hline 7.5 & $120+10.0$ & $18.1+7.30$ & $1.67+0.221$ & $412+132.6$ & $3.3^{ \pm} 1.06$ & $4.70+2.049$ \\
\hline \multirow[t]{4}{*}{15.0} & $180 \pm 0.0$ & $50.8 \pm 4.65$ & $5.24 \pm 1.387$ & $1204 \pm 184.9$ & $9.6 \pm 1.48$ & $4.28 \pm 0.495$ \\
\hline & \multicolumn{6}{|l|}{ Quality data } \\
\hline & \multicolumn{3}{|l|}{ Color } & \multirow{2}{*}{$\begin{array}{l}\text { Chloro, } \\
\text { SPAD }\end{array}$} & \multirow{2}{*}{$\begin{array}{l}\text { Antho, } \\
\mu \mathrm{g} \mathrm{g}^{-1} \mathrm{FM}\end{array}$} & \multirow{2}{*}{$\begin{array}{l}\text { ORAC } \\
\text { (TE/g FM) }\end{array}$} \\
\hline & $\mathrm{L}$ & a & $\mathrm{b}$ & & & \\
\hline 7.5 & $35.3 \pm 0.81$ & $16.6 \pm 0.76$ & $42.1 \pm 10.4$ & $15.2 \pm 0.95$ & $681 \pm 17.7$ & $53.7 \pm 1.58$ \\
\hline 15.0 & $34.8 \pm 0.05$ & $4.0 \pm 8.40$ & $29.0 \pm 12.59$ & $22.3 \pm 1.15$ & $633 \pm 30.2$ & NO DATA \\
\hline
\end{tabular}

Osmocote $=$ Osmocote Plus 15-9-12, Scotts, Maryville, $\mathrm{OH}$

FM and DM $=$ Fresh mass and dry mass, respectively.

$\mathrm{LAI}=$ Leaf area index in $\mathrm{m}^{2}$ of leaves above $\mathrm{a}^{2}$ of ground area.

SLM $=$ Specific leaf mass, which measures the density of leaf tissue.

SPAD values refer to readings taken with a commercial chlorophyll detection meter.

Antho $=$ Anthocyanin, or the reddish / purple pigment in plants which is an antioxidant. 
ORAC $=$ Oxygen Radical Absorbance Capacity and is a measure of antioxidant capacity.

The response of Firecracker was consistent to that of Outredgeous, in that increasing the concentration of Osmocote ${ }^{\circledR}$ from 7.5 to $15 \mathrm{~g} / \mathrm{L}$ of media resulted in a $65 \%$ increase in plant height, a $3 \mathrm{X}$ increase in $\mathrm{FM}, 2.9 \mathrm{x}$ increase in DM and 4X increase in leaf area (Table 7). This is reflected in the 2.6X higher LAI, as well as slight increase in SLM.. As with Outredgeous, increasing the concentration of Osmocote ${ }^{\circledR}$ also resulted a reduction in the $\mathrm{a}^{*}$ and $\mathrm{b}^{*}$ color values, which produces a less intense purple color of the leaf. There was an increase in chlorophyll concentration, and slight reduction (7\%) in anthocyanin concentration. The instrumentation for measuring ORAC failed and could not be repaired, so it's not possible to assess the effect on antioxidant potential at this time.

The increase in plant size is likely due to the higher concentration of $\mathrm{N}$ in media, which is consistent with the higher concentration of chlorophyll in the leaf. The reduction in fresh mass, with higher leaf area, may be due to relatively low percentage of blue light in the VEGGIE LED array spectrum, which would result in leaf expansion.

Table 2: Effect of Osmocote ${ }^{\circledR}$ concentration on the growth and quality of Lettuce cv. Firecracker grown on commercial peat/vermiculate mix under VEGGIE LED array ((mean + standard error) .

\begin{tabular}{|l|l|l|l|l|l|l|}
\hline & \multicolumn{6}{|l|}{ Biometric Data } \\
\hline $\begin{array}{l}\text { Osmocote } \\
{[\mathrm{g} / \mathrm{L}]}\end{array}$ & $\begin{array}{l}\text { Height } \\
(\mathrm{mm})\end{array}$ & $\begin{array}{l}\text { FM } \\
\mathrm{g})\end{array}$ & $\begin{array}{l}\mathrm{DM} \\
(\mathrm{g})\end{array}$ & $\begin{array}{l}\text { Leaf Area } \\
(\mathrm{cm} 2)\end{array}$ & LAI & $\begin{array}{l}\text { SLM } \\
(\mathrm{mg} / \mathrm{cm} 2)\end{array}$ \\
\hline 7.5 & $115 \pm 15.0$ & $12.9 \pm 0.47$ & $1.35 \pm 3.484$ & $375 \pm 93.9$ & $3.0 \pm 0.53$ & $3.49 \pm 0.640$ \\
\hline 15.0 & $190 \pm 10.0$ & $38.8 \pm 1.19$ & $3.90 \pm 0.325$ & $983 \pm 53.4$ & $7.9 \pm 0.43$ & $3.99 \pm 0.547$ \\
\hline \multicolumn{7}{|l|}{} \\
\hline
\end{tabular}

Osmocote $=$ Osmocote Plus 15-9-12, Scotts, Maryville, $\mathrm{OH}$

$\mathrm{FM}$ and $\mathrm{DM}=$ Fresh mass and dry mass, respectively.

$\mathrm{LAI}=$ Leaf area index in $\mathrm{m}^{2}$ of leaves above $\mathrm{a} \mathrm{m}^{2}$ of ground area.

SLM $=$ Specific leaf mass, which measures the density of leaf tissue.

SPAD values refer to readings taken with a commercial chlorophyll detection meter.

Antho $=$ Anthocyanin, or the reddish $/$ purple pigment in plants which is an antioxidant.

ORAC $=$ Oxygen Radical Absorbance Capacity and is a measure of antioxidant capacity.

The response of the green bibb-leaf cultivar Flandria was similar to that of Outredgeous and Flandria in that increasing the concentration of Osmocote $\AA$ from 7.5 to $15 \mathrm{~g} / \mathrm{L}$ of media resulted in a $65 \%$ increase in plant height, 2.3X increase in FM, 2.3X increase in DM and 2.5X increase in leaf area (Table 8). This is reflected in the $2.5 \mathrm{X}$ higher LAI. There was no significant difference in the SLM. There is negligible concentration of anthocyanin pigments in the green-leaf Flandria cultivar, so no change in color, chlorophyll or anthocyanin concentrations were detected. The instrumentation for measuring ORAC failed and could not be repaired, so it's not possible to assess the effect on antioxidant potential at this time. The increase in plant size is likely due to the higher concentration of $\mathrm{N}$ in media, 
Table 3: Effect of Osmocote ${ }^{\circledR}$ concentration on the growth and quality of Lettuce cv. Flandria grown on commercial peat/vermiculate mix under VEGGIE LED array (mean + standard error) .

\begin{tabular}{|c|c|c|c|c|c|c|}
\hline & \multicolumn{6}{|c|}{ Biometric Data } \\
\hline $\begin{array}{l}\text { Osmocote } \\
{[\mathrm{g} / \mathrm{L}]}\end{array}$ & $\begin{array}{l}\text { Height } \\
(\mathrm{mm})\end{array}$ & $\begin{array}{l}\text { FM } \\
(\mathrm{g})\end{array}$ & $\begin{array}{l}\text { DM } \\
(\mathrm{g})\end{array}$ & $\begin{array}{ll}\begin{array}{l}\text { Leaf } \\
\left(\mathrm{cm}^{2}\right)\end{array} & \text { Area } \\
\end{array}$ & LAI & $\begin{array}{l}\text { SLM } \\
(\mathrm{mg} / \mathrm{cm} 2)\end{array}$ \\
\hline 7.5 & $87.5 \pm 12.50$ & $16.7 \pm 2.13$ & $1.72 \pm 0.494$ & $382 \pm 30.0$ & $3.1 \pm 0.24$ & $4.45 \pm 0.945$ \\
\hline \multirow[t]{2}{*}{15.0} & $120 \pm 10.0$ & $39.3+0.87$ & $4.59+2.371$ & $956+82.2$ & $7.7 \pm 0.66$ & $4.62+2.083$ \\
\hline & \multicolumn{6}{|l|}{ Quality data } \\
\hline \multirow[b]{2}{*}{ [Conc] } & \multicolumn{3}{|l|}{ Color } & \multirow{2}{*}{$\begin{array}{l}\text { Chloro } \\
\text { (SPAD) }\end{array}$} & \multirow{2}{*}{$\begin{array}{l}\text { Antho } \\
\text { (ug/g FM) }\end{array}$} & \multirow{2}{*}{$\begin{array}{l}\text { ORAC } \\
\text { (TE/g FM) }\end{array}$} \\
\hline & $\mathrm{L}$ & $\mathrm{a}$ & $\mathrm{b}$ & & & \\
\hline 7.5 & $50.0 \pm 0.97$ & $-21.2 \pm 0.20$ & $35.8 \pm 0.97$ & $23.6 \pm 0.85$ & N.D. & $54.5 \pm 2.74$ \\
\hline 15.0 & $48.7 \pm 3.00$ & $-20.2 \pm 0.78$ & $32.2 \pm 0.94$ & $23.0 \pm 2.10$ & N.D. & NO DATA \\
\hline
\end{tabular}

Osmocote= Osmocote Plus 15-9-12, Scotts, Maryville, $\mathrm{OH}$

FM and DM = Fresh mass and dry mass, respectively.

$\mathrm{LAI}=$ Leaf area index in $\mathrm{m}^{2}$ of leaves above $\mathrm{a} \mathrm{m}^{2}$ of ground area

SLM $=$ Specific leaf mass, which measures the density of leaf tissue.

SPAD values refer to readings taken with a commercial chlorophyll detection meter.

Antho $=$ Anthocyanin, or the reddish / purple pigment in plants which is an antioxidant.

ORAC $=$ Oxygen Radical Absorbance Capacity and is a measure of antioxidant capacity.

Increasing the concentration of prills of the controlled release fertilizer from 7.5 to $15 \mathrm{~g} / \mathrm{L}$ resulted in significant increase in plant height, FM, DM and leaf area of all three cultivars. There was a reduction in pigmentation of the red-leafed cultivars, but they still had acceptable coloration, and size. The recommendation was to utilize the $15 \mathrm{~g} / \mathrm{L}$ concentration in the commercial peat/vermiculite mix during field testing of the system in the HDU.

\section{Development of a Hazard Analysis and Critical Control Point (HACCP) Plan to minimize risk of consumption of fresh lettuce.}

The objective of these experiments were to identify risks associated with the consumption of fresh lettuce grown in a closed environment of the HDU PEM and provide recommendations to control those risks.

The HACCP recommends that good manufacturing practices be followed to limit microbial contamination during the production, harvest and processing of the lettuce. The HACCP recommends sanitation protocols as a primary or prophylactic treatment to ensure that the total aerobic count of micro organisms is less than the $2 \times 10^{4}$ colony forming units (CFU) per gram fresh mass required meeting the ISS microorganism tolerance standard for nonthermostabilized food products.

There are numerous chemical agents that are effective in inactivating pathogenic microorganisms, but unfortunately they often have disadvantages that make them less than ideal. Some sanitizers may stain surfaces, may be highly corrosive, leave films on the surface and may impart an off-flavor to freshly prepared foods. Other chemicals may be too costly or extremely hazardous to employees.

Three candidate sanitizers considered for HDU PEM VEGGIE grown lettuce were $200 \mathrm{ppm}$ hypochlorite dip, 5\% hydrogen peroxide dip, and 2\% Pro-San ${ }^{\circledR}$ (Microside, Inc, Troy, MI) dip.

Chlorine sanitizers are the most commonly used chemicals in the processing of fresh produce, as well as the sanitization of equipment and utensils. Chlorine is readily available, inexpensive, and effective. The amount of hypochlorous acid ( $\mathrm{HOCl}$, the active sanitizing agent) that is formed in solution is a function of the $\mathrm{pH}$ of solution. A lower $\mathrm{pH}$ level fosters $\mathrm{HOCl}$ formation, with a solution of $\mathrm{pH} 5$ having nearly all chlorine in the $\mathrm{HOCl}$ form. A higher $\mathrm{pH}$ increases the formation of hypochlorite $\left(\mathrm{OCl}^{-}\right)$ions, and thus decreases the efficacy of chlorine-based sanitizers. When the $\mathrm{pH}$ is at 4.0 or lower, deadly chlorine $\left(\mathrm{Cl}_{2}\right)$ gas (mustard gas) can form, and this could be a 
safety and health concern due to irritations to the skin and can cause damage to mucous membranes. The use of Chlorine sanitizers thus requires that $\mathrm{pH}$ be closely monitored and control to ensure efficacy and safety.

Hydrogen peroxide $\left(\mathrm{H}_{2} \mathrm{O}_{2}\right)$ is also a commonly used and highly effective disinfectant against pathogenic bacteria, fungi, algae, viruses and amoebae. Hydrogen peroxide degrades into hydrogen and oxygen and is generally recognized as safe. Fruits and vegetables treated with hydrogen peroxide have an extended shelf-life. Hydrogen peroxide is available in various classes of concentrations. As the concentration increases, so do concerns of material handling. $\mathrm{H}_{2} \mathrm{O}_{2}$ solutions below an $8 \%$ concentration fall into the non-regulated safety code class. $\mathrm{H}_{2} \mathrm{O}_{2}$ solutions between $8 \%$ and $20 \%$ are considered a Class I Oxidizer, but are not themselves flammability concerns. At concentrations above $20 \%$, flammability becomes an increasingly more serious concern. Hydrogen peroxide breaks down with storage, so it's critical to maintain appropriate temperature and $\mathrm{pH}$ conditions to maintain efficacy.

PRO-SAN ®is a relatively new food grade, biodegradable sanitizer that is marketed by Microcide, Inc.(Troy, MI). NASA Food Technology for Commercial Space Center (FTCSC) as an affiliate partner, with sponsorship from Glenn Research Center-sponsored Garrett Morgan Commercialization Initiative (GMCI) and was awarded a Small Business Innovative Research (SBIR) grant to develop formulations suitable for long duration space missions.

PRO-SAN $\left({ }^{2}\right.$ has been shown to reduce numbers of Salmonella and E. coli O157:H7 on tomatoes by about 3 log cycles (1,000-fold) (Mendonca et al., 2004). The active sanitizing agents in PRO-SAN $®$ are citric acid $(66 \%)$ and sodium dodecylbenzene sulfonate (3.6\%). Inert ingredients composed the remaining $30.4 \%$ of the powered concentrate. The inclusion of the surfactant (sodium dodecylbenzene sulfonate) and citric acid in the PRO-SAN $®$ formulation increase the "wetting" properties of a solution which enhances its capability to release water-insoluble organic compounds that are bound to a food-contact surface.

In tests conducted with lettuce grown under the VEGGIE LED light array, soaking the freshly harvested lettuce in a $2 \%$ PRO-SAN ${ }^{\circledR}$ solution reduced microbial contamination on lettuce to undetectable levels $(<21 \mathrm{CFU} / \mathrm{g})(\mathrm{Orbitec}$, personal communication). This result was not surprising considering the relatively low initial bacterial counts on non-washed lettuce harvested from VEGGIE. Therefore, a combination of hygienic handling of the harvested lettuce and sanitization of this vegetable with PRO-SAN ${ }^{\circledR}(2 \%)$ has proven to be an excellent approach for reducing the microbial load on lettuce. Although no shelf-life evaluation was conducted, it is probable that the low microbial counts of sanitized VEGGIE-grown lettuce would significantly delay spoilage and thus extend the shelf-life of lettuce during refrigeration. This will not be an issue due to the short (14 d) duration of the HDU PEM DRAT test.

Table 4: Existing food safety protocols used to establish baseline for empirical testing for the HDU PEM food system HACCP.

\begin{tabular}{|c|c|c|c|}
\hline REFERENCE & APPLICATION & TREATMENT & NOTES \\
\hline JSC HSP Crew Ops ${ }^{1}$ & $\begin{array}{l}\text { JSC Food Safety } \\
\text { space systems }\end{array}$ & $\begin{array}{l}200 \text { ppm Chlorine } \\
\text { dip for } 30 \mathrm{sec}\end{array}$ & No rinse \\
\hline Bio-Plex HACCP2 & $\begin{array}{l}\text { Gravity based } \\
\text { closed system }\end{array}$ & $\begin{array}{l}3 \% \mathrm{H}_{2} \mathrm{O}_{2} \text { dip for } 2 \\
\text { min }\end{array}$ & $\begin{array}{l}\text { Rinse w/ potable } \\
\text { water }\end{array}$ \\
\hline VEGGIE HACCP ${ }^{3}$ & $\begin{array}{l}\text { Microgravity based } \\
\text { open system }\end{array}$ & $\begin{array}{l}2 \% \text { PRO-SAN } \\
\text { solution for } 3 \mathrm{~min}\end{array}$ & $\begin{array}{l}\text { Rinse w/ potable } \\
\text { water }\end{array}$ \\
\hline 21 CRF Part $173^{4}$ & $\begin{array}{l}\text { Commercial } \\
\text { production system }\end{array}$ & $\begin{array}{l}500-1200 \text { Chlorine } \\
\text { ppm dip for } 1 \mathrm{~min}\end{array}$ & $\begin{array}{l}\text { Rinse w/ potable } \\
\mathrm{H}_{2} \mathrm{O}\end{array}$ \\
\hline $\begin{array}{l}\text { Email correspondence } \\
\text {. Email submission of Bi } \\
2001 \\
\text { Orbitec VEGGIE SBIR P }\end{array}$ & $\begin{array}{l}\text { Kloeris (JSC-SF311) on } 4 \\
\text { Plex HACCP Plan fro Lettu } \\
\text { ase II (OTC-GS0140-FR-07 }\end{array}$ & $\begin{array}{l}2010 \\
\text { Spinach and Leafy Herb }\end{array}$ & $\begin{array}{l}\text { A. Toerne on } 24 \text { January, } \\
r y, 2007\end{array}$ \\
\hline
\end{tabular}

\section{A. Experimental protocols}

1. Plant material: Lettuce cv. Flandria, Outredgeous, and Firecracker were grown under compact fluorescent lamps (CFL) lamps in either arcillite or peat vermiculite in under conditions anticipated for the HDU PEM. Lettuce was 
harvested at 28 DAP by removing the plant at the base. Leaf area, fresh mass, and plant height were determined for each plant prior to microbial analysis.

2. Treatments: The leaves were cut off at the base using scissors, soaked for three minutes in the $200 \mathrm{ppm}$ hypochlorite solution, $3 \%$ hydrogen peroxide $\left(\mathrm{H}_{2} \mathrm{O}_{2}\right)$, or $2 \%$ PRO-SAN $®$ in an open container for 2 minutes, and rinsed for 2 minutes in deionized water prior to microbial enumeration.

3. Microbial enumeration: Aseptically weighed samples of Outredgeous, Flandria and Firecracker subjected to each sanitizing protocol as described above were rinsed with deionized water and placed in sterile mixer bags (Baglight, Interscience labs, Weymouth, MA).Sterile buffered peptone water (BPW) was added to the bags resulting in a 1:10 $\mathrm{w} / \mathrm{v}$ dilution. Samples were macerated in a Bagmixer lab blender for 2 minutes. The liquid was serially diluted and $100 \mathrm{ml}$ of the appropriate dilutions were plated in duplicate onto plate count agar (PCA) for the enumeration of aerobic bacteria and inhibitory mold agar (IMA) for the enumeration of yeast and mold. PCA plates were incubated for 48 hours at $30^{\circ} \mathrm{C}$ and IMA plates at $25^{\circ} \mathrm{C}$ for 5 days. Agar media used for plating was obtained from Difco (Beckton Dickenson and Co. Sparks, Md). After incubation, colonies were counted to determine colony forming units (CFU)/gram fresh weight of lettuce.

\section{B. Results}

The effect of each treatment on the reduction in aerobic bacterial, yeast, and mold counts for each cultivar is shown below in Table 5. PRO-SAN $®$ was as good as, or better than the $200 \mathrm{ppm}$ Chlorine rinse, currently used by the NASA Food Safety Group, at reducing aerobic bacteria, yeast, and mold levels. This was especially true with Outredgeous, which has more of a crinkled leaf surface than either Flandria or Firecracker.

Table 5. Average percent reduction in aerobic bacterial (APC) and yeast and mold counts on lettuce leaves subjected to sanitizing treatments.

\begin{tabular}{|c|c|c|c|}
\hline \multicolumn{4}{|c|}{ APC $(\%$ reduction $)$} \\
\hline & Bleach & PRO-SAN & $\mathrm{H}_{2} \mathrm{O}_{2}$ \\
\hline Flandria & 85 & 93 & 91 \\
\hline Firecracker & $>99$ & $>99$ & 72 \\
\hline Outredgeous & 35 & 89 & $>99$ \\
\hline \multicolumn{4}{|c|}{ Yeast and Mold ( $\%$ reduction) } \\
\hline & Bleach & PRO-SAN & $\mathrm{H}_{2} \mathrm{O}_{2}$ \\
\hline Flandria & 97 & $>99$ & 93 \\
\hline Firecracker & $>99$ & $>99$ & 87 \\
\hline Outredgeous & 74 & $>99$ & 96 \\
\hline
\end{tabular}

PRO-SAN $®$ had a 2 to 3 fold log reduction in the total counts on Flandria and Firecracker. It should be noted that production protocols resulted in relatively low microbial counts at harvest. In fact, the maximum counts were below the NASA standard of $1 \times 10^{4} \mathrm{CFU} / \mathrm{g}$ FM for thermally stabilized foods (data not shown) This suggests that production in a relatively closed environment, will limit the potential for contamination, and that PRO-SAN ${ }^{\circledR}$ treatment significantly reduces the remaining microbial load.

The microbial load on the plant tissue was below the NASA standard of $1 \times 10^{4} \mathrm{CFU} / \mathrm{g}$ FM when harvested. This is not unexpected, given that the plants were grown in a controlled environment with limited opportunities for contamination. However, it should be noted, that the plants did receive routine horticultural maintenance, and daily checks during the 28 day growth cycle. This suggests that the operations developed minimize external contamination from the environment. There were no known human pathogens identified in the samples.

Both the $2 \%$ ProSan ${ }^{\circledR}$ rinse and the $200 \mathrm{ppm} \mathrm{Cl}$ - rinse removed over $98 \%$ of the microbial load, and were both more effective the $3 \% \mathrm{H}_{2} \mathrm{O}_{2}$ dip. The $2 \%$ ProSan ${ }^{\circledR}$ was as effective as Chlorine, without the associated hazards of handling $\mathrm{Cl}-$, or the appearance of off-flavors. 
As such, ProSan ${ }^{\circledR}$ is the recommended sanitizer for use in the HDU PEM VEGGIE DRAT test for the following reasons:

- It is effective at killing a wide range of food-borne microorganisms, including A. hydrophila, E. coli, L.monocytogenes, P. aeruginosa, S.typhimurium, S.aureus, S. sonnei, Vibrio cholera, and Yersina eterocolintica.

- It is an EPA registered (no. 71094-1) sanitation agent with no restricted use limitations.

- It is readily packaged, and requires only DI water preparation.

- It is stable under ambient temperature conditions.

- It is as effective than $200 \mathrm{ppm}$ hypochlorite solutions for reducing the concentration of microorganisms grown under mission relevant conditions.

- It is as effective as $5 \% \mathrm{H}_{2} \mathrm{O}_{2}$ at sanitizing food surfaces.

- It is biogradable, and leaves no toxic residue.

- It is free of volatile organic compounds, and does not result in contamination of the atmosphere.

- Fruits and vegetables treated with it have an extended shelf-life.

- As a non-oxidizing sanitizer, it does not induce browning or discoloration, as has been reported for 5-10\%, hydrogen peroxide.

\section{Lettuce growth in the HDU Food production System}

A primary objective of the DRAT field test was to demonstrate the operational performance of the VEGGIE LED food performance in an integrated test of surface operations at an analog test site. The 2010 DRAT test was the first test to include PEM, and was the first to include technology demonstration of a food production system. The 14 day duration of the test was insufficient to develop a salad crop to horticultural maturity, so pre-established plants used for this testing.

\section{A. HDU operations.}

In order to provide plant material of the appropriate age, three lettuce cultivars, Outredgeous, Flandria and Firecracker, were started in a commercial peat vermiculite mix with controlled release fertilizer in the controlled environment labs at KSC as described above. At $14 \mathrm{DAP}$, the plants were removed from the growth chamber, covered with a protective shell, and hand-carried to the Black Point Lava Flow test site north of Flagstaff, AZ. Two sets of plants were planted to function as "control treatments" for growth during the test.

The BP Lava Flow Site is located 35 miles north of Flagstaff, AZ on property owned by the Babbitt Ranch. The HDU PEM had been previously transported from JSC to BP lava flow site (Fig. 1).
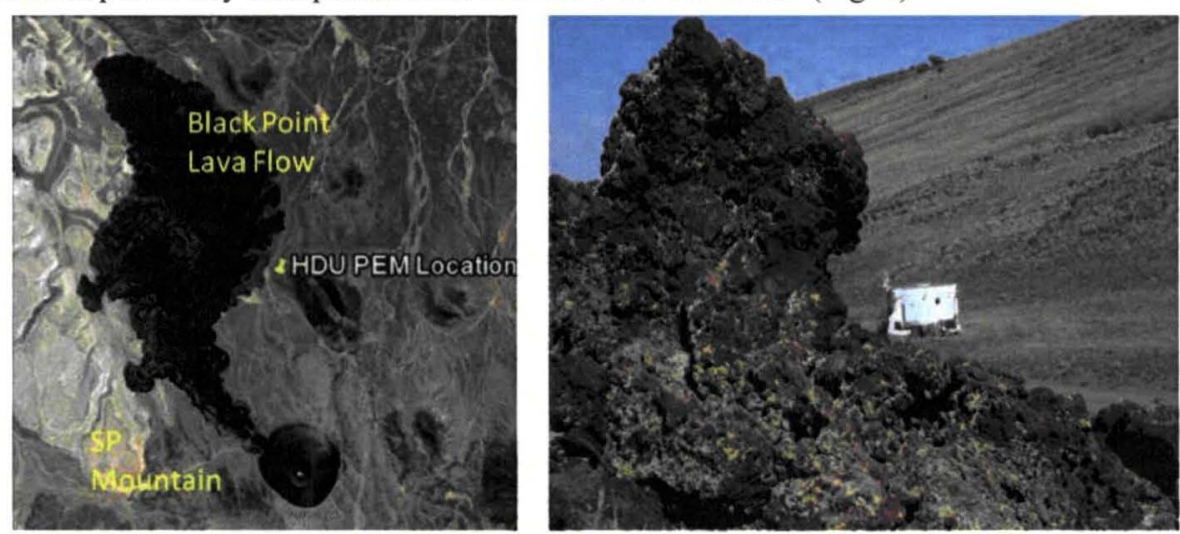

Figure 11: Initial location of the HDU PEM relative to the Black Point Lava Flow from SP Mountain, north of Flagstaff, AZ (Left) and view of the HDU from the edge of the BP lava flow (Right). 
After installation, the nutrient delivery system was primed, and allowed to equilibrate. Following equilibration, the food system was left for "autonomous operation" by the DRAT crew, and HDU "ground support" personnel (Fig. 2).
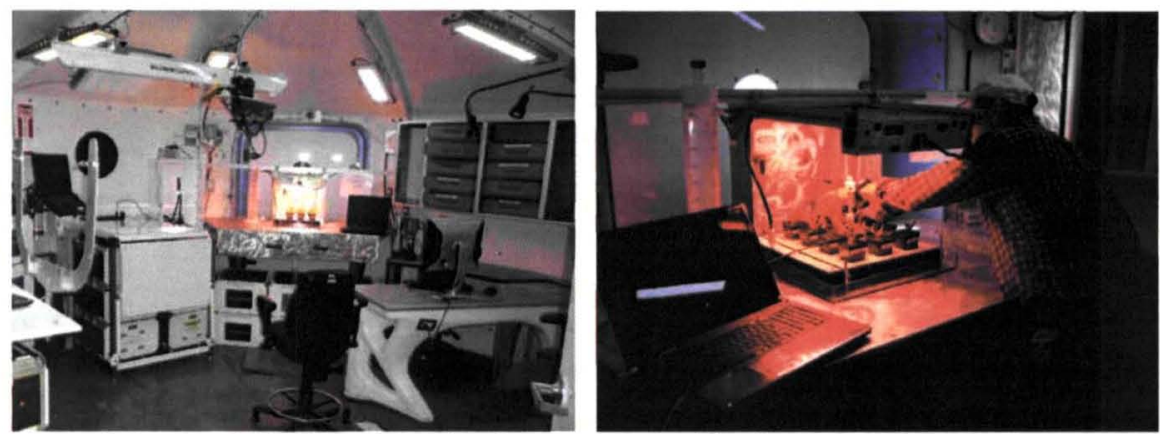

Figure 2: Location of the VEGGIE Food Production system inside the HDU PEM at the start of DRAT testing (Left). The Suit work station and General Workstation are to the Left of the VEGGIE LED array and Medical workstation and supply storage are to the right. Lettuce plants started at KSC and hand-carried to the test site were installed under the VEGGIE LED array and the nutrient delivery system activated (Right).

The three lettuce cultivars were placed in the rooting tray and allowed to grow. They adapted well to the change in environment, and their growth and development were monitored by the HDU PEM ground support crew at the BP Lava Flow site (Fig. 3).
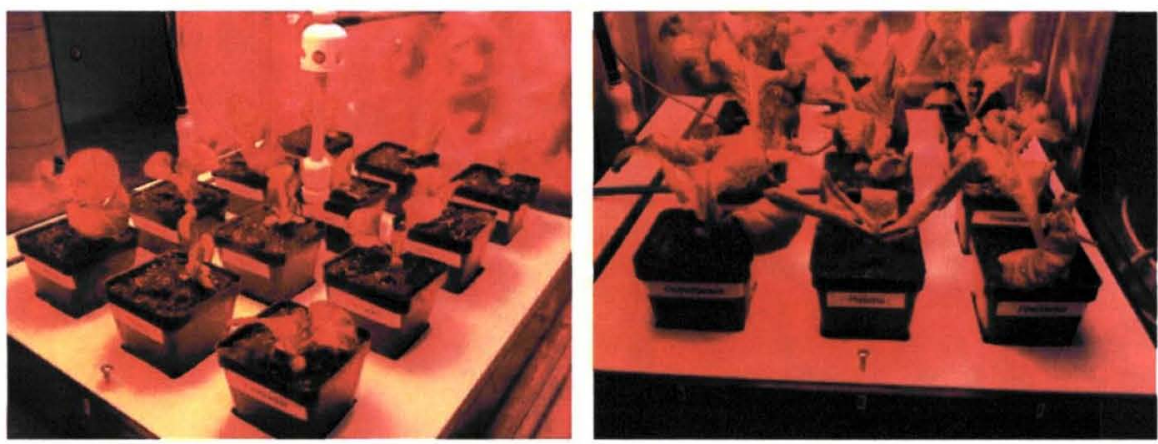

Figure 3: Lettuce plants were installed into the VEGGIE rooting tray at the start of the 2010 DRAT tests (Left) and growth supported throughout the nutrient delivery system. The same plants at Day 4 of the 2010 DRAT test (Right).

At 7 days into the DRAT test site, the two Surface Exploration Vehicles (SEVs) and crew members docked with HDU PEM. The crew performed replenishment of the nutrient reservoir and provided positive feedback on the growth of the plants (Fig 4).
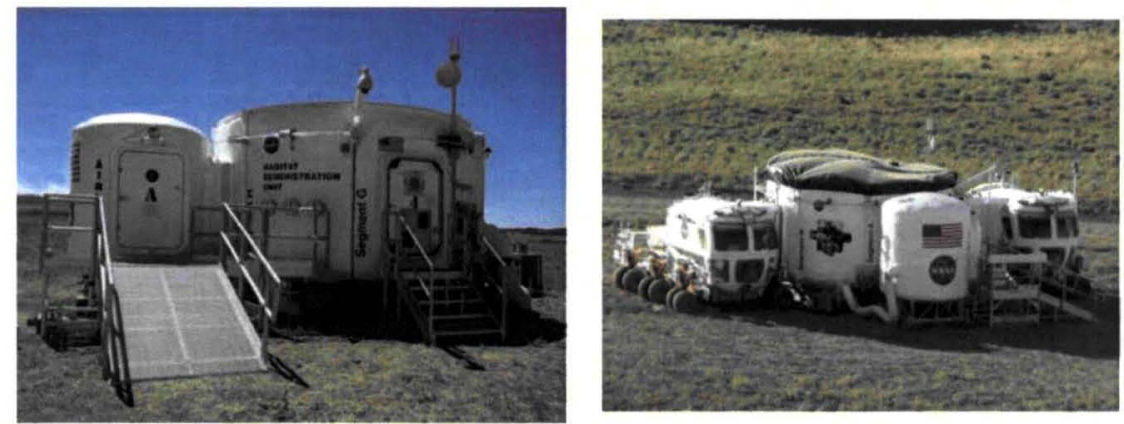

Figure 4: View of the HDU PEM at the BP lava flow site prior to docking of the SEV's (Left). Overview of the two surface exploration vehicles (SEV's) docked to the HDU PEM at day 7 of the 2010 DRAT test (Right).

10

American Institute of Aeronautics and Astronautics 
Following de-docking, the HDU PEM was unpowered, and transported $\sim 7$ miles $(11.3 \mathrm{~km})$ to the DRAT Base Camp. The rooting tray with plants was removed from the PEM during this time (Fig. 5).
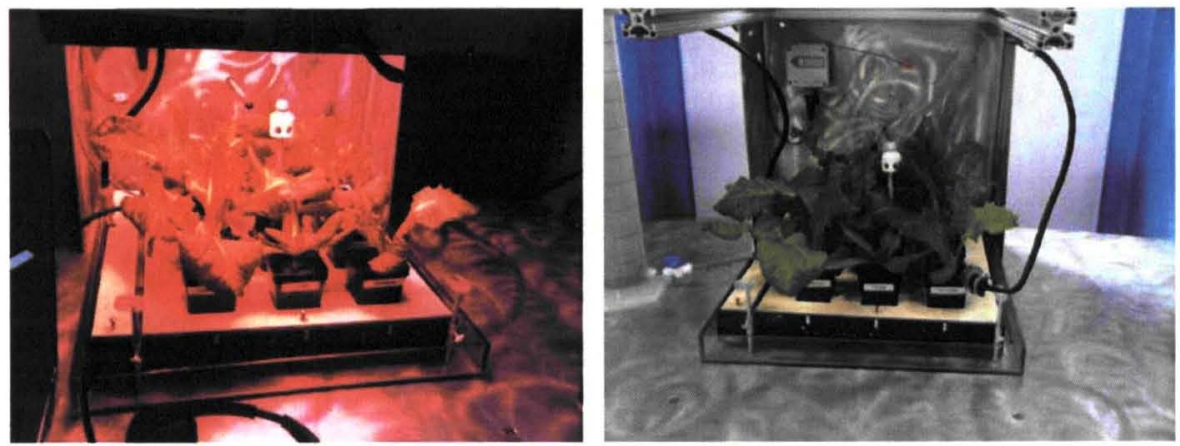

Figure 2: Size of lettuce plants under the VEGGIE LED array at day 8 of the 2010 DRAT test prior to removal from the HDU PEM (Left). Growth and coloration of the lettuce at day 8 of the 2010 DRAT test after the VEGGIE LED array had been powered down. Notice the lack of pigmentation in the leaves of the red-leafed cultivars Outredgeous and Firecracker (Right).

Following the move of the PEM, the lettuce were reinstalled under the VEGGIE LED array, and allowed to develop until the next crew docking on September $13^{\text {th }}$ (Fig 7).
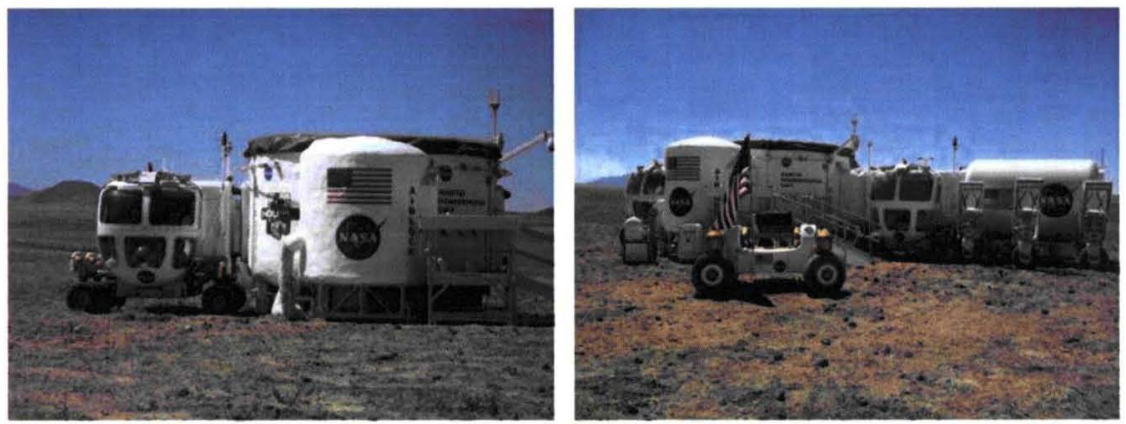

Figure 3: View of the HDU PEM at the DRAT Base Camp with SEV preparing to dock (Left). A view of the two SEV's, HDU PEM and ATHLETE in docked configuration at the DRAT base camp. The Centaur vehicle is in the foreground (Right).

On September $13^{\text {th }}$, prior to docking of the SEVs, half of the plants were harvested and plant height, width, and leaf number obtained (Fig. 8).
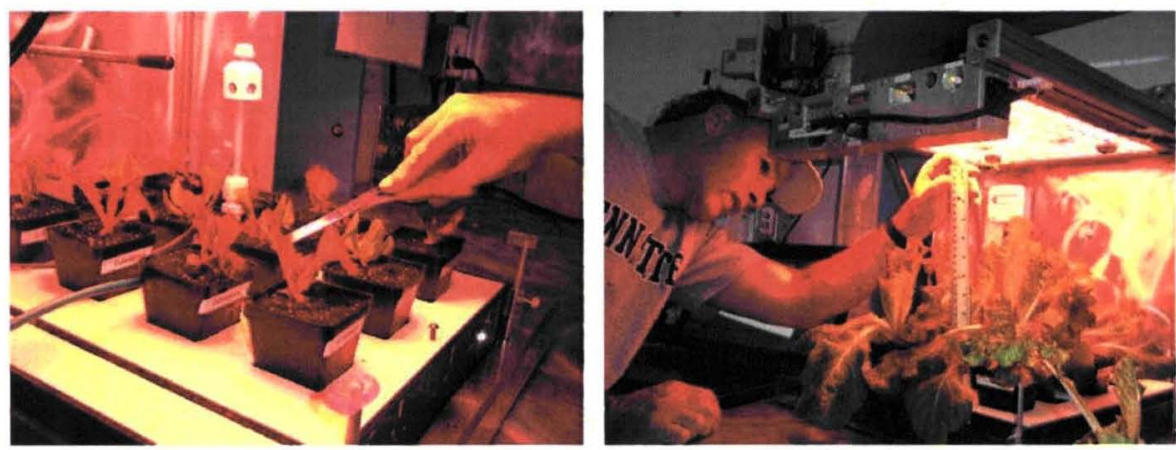

Figure 4: Plant size at the start of DRAT testing on 30 August, 2010 (Left). Ray Wheeler taking plant height measurements at Day 14 of the DRAT test on 13 September, 2010 (Right). 
The harvested planted were sanitized following the approved HACCP procedures, and the crew was given approval to consume the lettuce as part of that day's lunch.
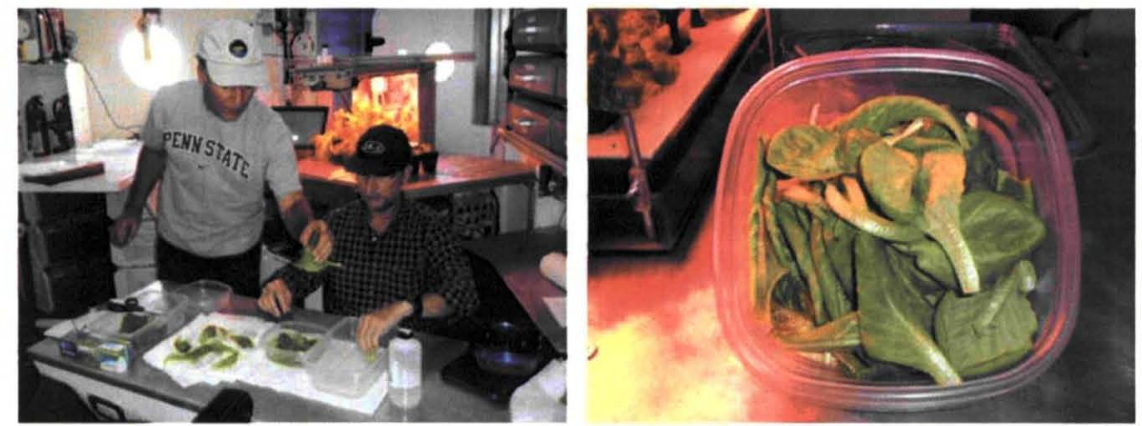

Figure 5: Ray Wheeler and Gary Stutte performing lettuce harvest and sanitation operations to validate crew procedures in the HDU PEM (Left). The sanitized lettuce leaves were left in the PEM for crew consumption (Right).

The remaining plants were maintained under the LED array to support Media, dignitary and Student outreach events (Figure 10).
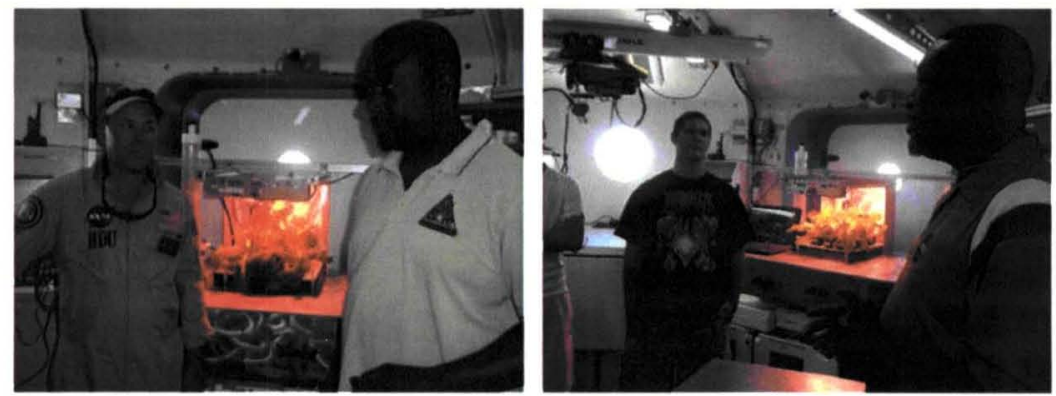

Figure 6: Dr.'s Scott Howe and Robert Howard provide an overview of the VEGGIE Food Production to the media and visiting VIP's (Left). Dr. Robert Howard explains to students the potential role of fresh plants on crew performance on long duration space missions (Right).

The plants were harvested on September $16^{\text {th }}$ and plant height, width and leaf number obtained. The harvested plants were sanitized and provided to the onsite HDU management and ground support team for lunch.

\section{B. Results}

All three lettuce cultivars grew very well under the operational constraints of the HDU PEM (Table 23). The height, width and leaf number of all three cultivars was greater than that of the control plants grown at KSC. Instrumentation was not available to obtain fresh mass, dry mass or colorimetric data.

Table 5. Height, width and leaf number of 28 day old lettuce harvested from VEGGIE HDU PEM DRAT test site compared to control plants grown at KSC in the Controlled Environment laboratory (mean \pm standard error).

\begin{tabular}{|l|l|l|l|l|l|l|l|l|l|}
\hline & \multicolumn{1}{|l}{ Firecracker } & \multicolumn{2}{l}{ Flandria } & \multicolumn{3}{|l|}{ Outredgeous } \\
\hline Location & $\begin{array}{l}\text { Height } \\
(\mathrm{cm})\end{array}$ & $\begin{array}{l}\text { Width } \\
(\mathrm{cm})\end{array}$ & $\begin{array}{l}\text { Leaves } \\
(\#)\end{array}$ & $\begin{array}{l}\text { Height } \\
(\mathrm{cm})\end{array}$ & $\begin{array}{l}\text { Width } \\
(\mathrm{cm})\end{array}$ & $\begin{array}{l}\text { Leaves } \\
(\#)\end{array}$ & $\begin{array}{l}\text { Height } \\
(\mathrm{cm})\end{array}$ & $\begin{array}{l}\text { Width } \\
(\mathrm{cm})\end{array}$ & $\begin{array}{l}\text { Leaves } \\
(\#)\end{array}$ \\
\hline DRAT & 15.75 & 29.25 & 8.25 & 7.50 & 23.00 & 10.25 & 19.25 & 35.0 & 9.50 \\
HDU & $(0.48)$ & $(2.69)$ & $(0.48)$ & $(1.19)$ & $(1.00)$ & $(0.48)$ & $(0.85)$ & $(2.86)$ & $(0.29)$ \\
\hline KSC & 11.75 & 25.25 & 6.75 & 9.75 & 14.25 & 9.75 & 13.50 & 24.5 & 7.25 \\
SLSL & $(1.60)$ & $(0.85)$ & $(0.63)$ & $(0.25)$ & $(0.48)$ & $(0.48)$ & $(0.65)$ & $(0.96)$ & $(0.25)$ \\
\hline
\end{tabular}

Data presented are means of 4 plants with the standard error of mean in parenthesis. 
The crew operations had called for a thinning of half the plants when docked to the HDU PEM at the BP Lava Flow site. However, there were operational constraints that eliminated that from the timeline. As a result, there was significant intracanopy shading of the plants. This resulted in significant shading of the green bibb-type cultivar Flandia (Fig 11). The shading, coupled with a relatively low percentage of blue light in the spectrum, resulted in elongation of the leaf petiole. This change in morphology did not appear to impact flavor, but certainly degraded the visual appeal of the plant.
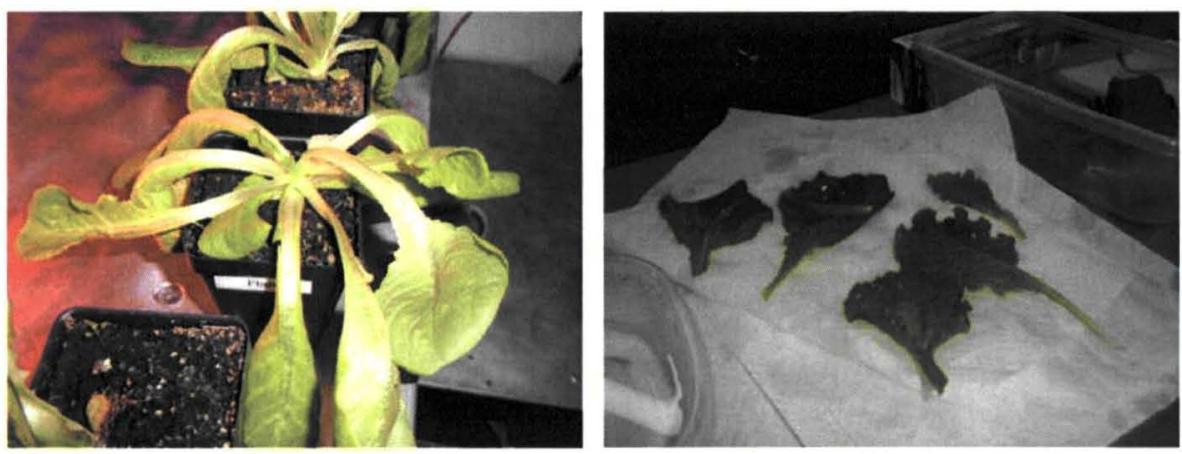

Figure 7: Effect of intra-canopy shading by Outredgeous and Firecracker cultivars on the petiole elongation of Flandria (Left). Large leaf blades and low concentrations of anthocyanin were observed in leaves of Outredgeous grown in the HDU PEM (Right).

Both the red leaf cultivars, Outredgeous and Firecracker, had leaf blades which were larger than those of comparable controls. This is also likely due to the relatively low percentage of blue light in the spectra. There was a subjective assessment, as the anthocyanin pigmentation had not developed as fully as expected (Fig. 11). It is not thought that this is associated with the spectra, since baseline analysis (see previous section) was conducted under the same VEGGIE LED array. This suggests that other components of the environment [e.g. $\mathrm{CO}_{2}$ concentration in the $\mathrm{HDU}$ PEM vs. SLSL CEL, differences in atmospheric pressure between KSC (sea level) and BP Lava Flow (6,200 ft)] are involved with anthocyanin formation.

Generally, there was excellent root growth in the media, and no obvious symptoms of water stress, anoxia, or salt stress were observed (Fig. 12).
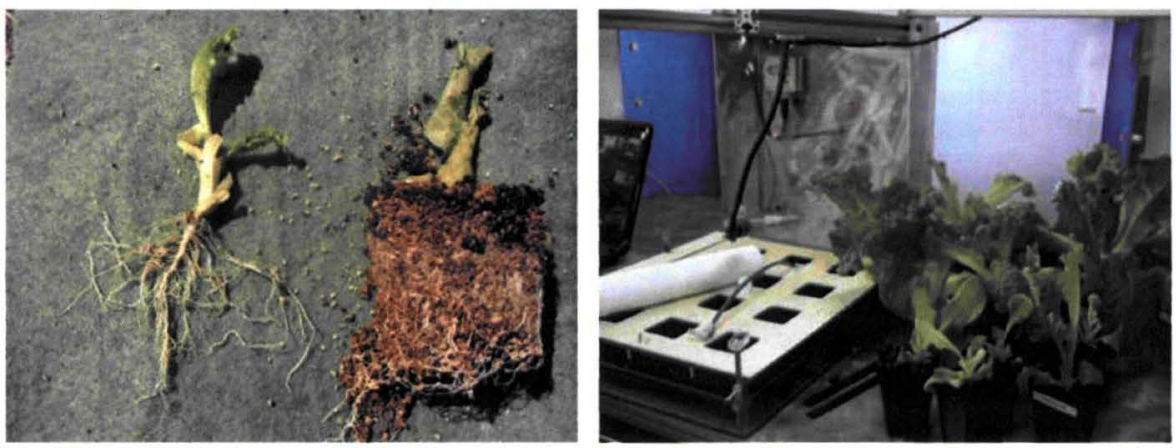

Figure 8: Roots were well distributed within the rooting media and showed no obvious signs of water stress or waterlogging (Left). All plants had good chlorophyll development and exhibited no obvious signs of nutrient deficiency or pathogen infection (Right).

At the final harvest on September 16th, it was noted that emerging leaves and leaf primoria remaining on the plant continued to expand. This demonstrates the potential for repeated harvests from the same plant during a longer duration mission. (Fig 13). 

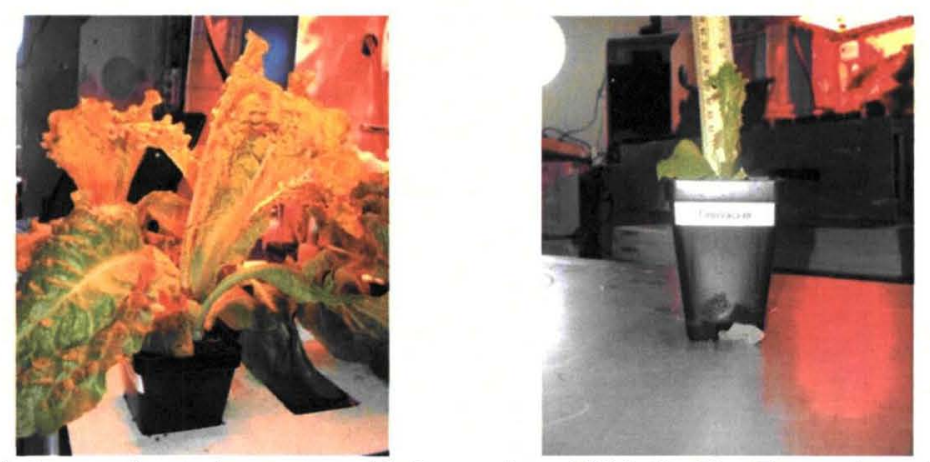

Figure 9: Firecracker lettuce prior to harvest on 13 September, 2010 (Left). Expansion of emerging leaves from harvested Firecracker after 3 days, on 16 September, 2010 (Right).

\section{Conclusion}

The 2010 DRATS test of the VEGGIE Food Production System in the Habitat Demonstration Unit (HDU) Pressurized Excursion Module (PEM) was the first operational evaluation of salad crop production technology in a NASA analog test. Extensive testing was performed determine nutrient delivery system to grow multiple lettuce cultivars with minimal crew intervention. A Hazard Analysis and Critical Control Point (HACCP) evaluation was performed. The resulting recommendations for sanitizing harvested lettuce were approved, and the crew was allowed to consume the produce. The 14 day DRAT field test validated the crew operations; Growth of all lettuce cultivars was excellent.

The operational field testing identified some issues with plant development related to morphology and pigment development that will need to be addressed through additional testing. Feedback from the crew, ground support personnel, and human factors leads was uniformly positive on the psychological value of having the crop production system in the PEM. A number of areas have been identified for future work, to minimize the "footprint" of the Food Production system through creative use of unused wall and floor space in the unit. These opportunities will be addressed when funding becomes available.

\section{Acknowledgments}

The authors thank Mary Hummerick and LaShelle McCoy for performing the microbial analysis for the HACCP testing and Tracy Gill, Kriss Kennedy, Terri Tri, Scott Howe, Ed Walsh, Michale C. Anderson, Verginia Yancy, Chris Chapman and Ronny Gambrell for their engineering, logistical, and operational support of the VEGGIE during the 2010 DRATS test. This research was supported through the NASA John F. Kennedy Space Centers FY10 Core Technical Capabilities Funding. 